\title{
BIBLIOGRAFIA
}

\section{Aportaciones a la Bibliografía de don José López Portillo y Rojas}

\author{
INTRODUCCION
}

$\mathbf{U}$

No de los novelistas más importantes de fines del siglo pasado en México; cuentista de primer rango de aquel tiempo, excepción hecha de los modernistas, es don José López Portillo y Rojas (1850-1923). Aparecen sus primeras obras novelísticas en el momento en que el realismo empieza a penetrar en este campo aunque tiene todavía, como casi todos los realistas del siglo diecinueve en Hispanoamérica, sus dejos de romanticismo. Parece no haberse interesado en las teorías de los modernistas. Al contrario, en una época en que era grande el desinterés en las cosas de España, es notable su afición por los escritores españoles, especialmente por el novelista Pereda. Solamente la muerte de este escritor impidió el que Los precursores apareciese con prólogo del notable español. 1

Es La parcela la más conocida de sus obras, pero habrían bastado las novelas cortas de López Portillo por sí solas para asegurar su fama. Realistas como La horma de su zapato, de tono sentimental y algo románticas como $E l$ primer amor, puros cuadros costumbristas en otros casos, se halla una variedad interesante en esta parte de su producción.

$Y$ aunque sobresale don José en el campo de la novela, abarcan sus obras la poesía, el drama, la historia, la crítica literaria y el artículo periodístico sin pretensiones más que momentáneas. No se 
trata aqui de avalorar su obra total, sino de presentar unas aportaciones, por incompletas que sean, a la bibliografia del insigne mexicano.

Con el título del presente trabajo, tratamos de indicar la naturaleza incompleta de este estudio bibliográfico. Lo que falta aquí principalmente son las primeras producciones del autor, en especial las que aparecieron en revistas y periódicos de Guadalajara, los que no hemos podido ver. En su excelente artículo, El periodismo en Guadalajara, 1809-1914, ${ }^{2}$ el señor Juan B. Iguíniz señala los siguientes en que colaboró López Portillo: La civilización, Juan Panadero, La alianza literaria, El eco social, Un periódico, El foro jalisciense, Flor de lis y México libre e independiente.

Debo confesar también un lapso de memoria. En alguna parte encontré una referencia, ahora perdida, a dos poesías de don José en el Seguindo almanaque Caballero. Son Los niños, página 50, poesía que no figura en esta bibliografía, $y$ una segunda publicación del Homenaje a José Martí (véase el núm. 78) que se halla en la página 94 del mismo almanaque.

Las fichas de la presente bibliografía están divididas en secciones según los géneros. En cada sección están los títulos en orden alfabético y numerados, las obras de López Portillo en una serie y los estudios biográficos y críticos en otra. Hemos conservado la nomenclatura de volumen, tomo, año, etc., según el sistema de cada revista en que aparece una publicación, pero preferimos usar la abreviatura num. para cualquier revista o periódico, y $N^{o}$ para referirnos a las fichas de este trabajo. Hemos clasificado los títulos en las siguientes divisiones:

Primera parte - Obras del autor.

I. Novela. (Nos. 1-49.)

II. Poesía. (Nos. 50-103.)

III. Artículos literarios, etc. (Nos. 104-126.)

IV. Obras dramáticas. (Nos. 127-129.)

V. Obras varias. (Nos. 130-161.)

VI. Traducciones. (Nos. 162-165.)

Segunda parte - Trabajos referentes a López Portillo.

(Nos. 1-42.) 
En las fichas de poesía hemos dado el primer verso de las composiciones, en los casos en que no fijó el título de ellas López Portillo, o en que, por una razón u otra, existe la posibilidad de confusión entre poesías distintas.

Hemos comentado en la bibliografía los casos más notables de variaciones que existen entre la primera publicación de una obra y una publicación posterior. No se ha hecho público ningún estudio sobre los textos de las obras de López Portillo. Debiéramos decir aquí que contados son los casos en que no hay variación de texto en diferentes ediciones de las poesías y de las novelas. Son tan grandes los cambios introducidos en ciertas poesías al trasladarlas de las páginas de La república literaria, por ejemplo, a Armonías fugitivas (1892), la colección más completa que existe, que casi equivalen a poesías nuevas. Podría hacerse un interesante estudio de la técnica poética y novelística de López Portillo, a base de los cambios que introduce en sus obras.

No debo terminar sin expresar mis agradecimientos a mi buen amigo y colega, Ernest R. Moore, que leyó en manuscrito la bibliografí, y a la amable señorita Anne S. Pratt, que me ayudó con sus investigaciones en la biblioteca de la Universidad de Yale. Soy yo el único responsable de los errores que se hallen en esta bibliografía.

RALPh E. WARNER, Universidad de Colorado.

\section{N O T A S}

1 López Portillo y Rojas. Los precursores. México, Imp. de V. Agüeros, 1909. (Biblioteca de Autores Mexicanos, 69.) P. v.

2 En Anales del Museo Nacional de Arqueología, Historia y Etnografia, época 4a, t. vir, núm. 2 (enero a diciembre, 1932), especialmente pp. 301-2, $306,313,318,329,337-341,352,360,369,376$ у 386. 


\section{ABREVIATURAS}

Iguíniz, Bibliog. biog. Bibliografía biográfica mexicana. Véase la segunda parte, núm. 23.

Iguiniz, Bibliografía de novelistas mexicanos. Véase la segunda parte, núm. 24.

Iguíniz, El periodismo en

Guadalajara.

Monterde.

Moore, Obras criticas. Moore, Ernest R. Obras criticas y biogra-
ficas referentes a la novela mexicana anterior
al siglo XIX. En Revista Iberoamericana,
vol. III, núm. 5. (febrero, 1941), pp. 235-
264.
Moore, Ernest R. y James G. Bickley.
Mafael Delgado. Notas bibliográficas y cri-
ticas. En Revista Iberoamericana, vol. v,
núm. 2 (febrero, 1943), pp. 153-202.

Véase la segunda parte, núm. 25.

Monterde, Francisco. Bibliografia del teatro en México. Véase la segunda parte, núm. 31.

La rep. lit. La república literaria.

Nota: De no mencionarse otro lugar, toda revista citada es de México, D. F., con excepción de La república literaria, que se publicaba en Guadalajara. 


\section{PRIMERA PARTE — OBRAS DEL AUTOR}

\section{NOVELA}

1 Adalinda. Leycnda. En La rep. lit., año It, t. II (marzo 87-marzo 88), pp. 9-21.

En el $N^{\circ} 25$.

2 El arpa. En La rep. lit., año III. t. IV (marzo 88-marzo 89), pp. 705-710; año tv, t. v (marzo 89-marzo 90), pp. 559-572.

En el $\mathrm{N}^{\circ} 25$.

3 El billete de loteria. En los Nos. 26, 47.

4 El brazalete. En el $\mathrm{N}^{\circ} 25$.

5 La combleza. En el $N^{2} 16$.

6 En diligencia. En La rep. lit., año II, t. II (marzo 87-marzo 88), pp. 421-429, 504-516.

La primera entrega trae la firma: Yusuf-ben-Issa; la segunda: Yusuf-ben-issa.

En el $N^{2} 25$.

7 Un drama en tres horas. En los Nos. 26, 47.

8 El dolor y la bonra. En los Nos. 26, 47.

9 Egoismo trágico. En los Nos. 26, 47.

10 El espejo. En La rep. lit., año 1, t. II (septiembre 86-febrero 87), pp. 44-57, 65-72.

Con fecha: Guadalajara, agosto de 1879.

En el $\mathrm{N}^{\circ} 25$.

11 Evocación. En el $N^{\circ} 16$.

12 Experiencia en cabeza ajena. En La rep. lit., año I, t. I (marzoagosto 1886), pp. 212-216.

13 La fortuna se cansa. En La rep. lit., año In, t. II (marzo 87-marzo 88), pp. $165-178$. 
14 Fuertes $y$ débiles. Novela por José López Portillo y Rojas. México, D. F., editada por "Librería Española", sin año [1919]. (8), 523 pp., 2 h. (indice, erratas más notables).

Se cita en parte el prólogo de este libro en las "Notas bibliográficas" de Biblos, t. I, núm. 46 (29 noviembre, 1919), p. 2 .

15 La fuga. En La rep. lit., año rv, t. v (marzo 89-marzo 90), pp. 747-778.

En el $N^{\circ} 25$.

16 Historias, bistorietas y cuentecillos por José López Portillo y Rojas. París-México, Librería de la Vda. de Ch. Bouret, 1918. 448 pp.

A la vuelta de la ante-portada: Imprenta Francesa.

Prólogo con fecha: México, marzo 14 de 1918.

Contiene: Puro cbocolate, Por un caballo, Ramo de olivo, Reloj sin dueño, La combleza, Mi sobrina Alicia, ;Silencio, corazón! y Evocación.

17 La borma de su zapato. En Antologia de cuentos mexicanos. Selección y prólogo de Bernardo Ortiz de Montellano. Madrid, Editorial "Saturnino Calleja, S. A.", Copyright, 1926, pp. $35-58$.

En los Nos. 26,$45 ; 47$.

17a - En Cuatro siglos de literatura mexicana. Seleccionada por Ermilo Abreu Gómez, Jesús Zavala, Clemente López Trujillo, Andrés Henestrosa. México, Editorial Leyenda, S. A., 1946, pp. $915-923$.

18 La isla del paraíso. Leyenda. En La rep. lit., año I, t. I (marzoagosto, 1886), pp. 217-228.

19 Laz de rayo. En Revista azul, 1913.

-J. R. Spell, Mexican literary periodicals, PMLA, vol. LIV, núm. 3 (septiembre, 1939), p. 837.

En los Nos. 26, 47.

20 Mi sobrina Alicia. En el $N^{\circ} 16$. 
21 La mueca del diablo. En La rep. lit., año rv, t. v (marzo 89marzo 90), pp. 634-639, 660-672.

En el $N^{\circ} 25$ con el título: Un pacto con el diablo.

22 Nieves. En La rep. lit., año I, t. II (septiembre 86-febrero 87), pp. 257-271, 289-305, 321-337, 353-370.

En el $\mathrm{N}^{\circ} 25$.

23 Novelas cortas. Véanse los Nos. 25, 26.

24 Obras del licenciado don José López Portillo y Rojas, miembro correspondiente de la Academia Mexicana. Tomo t. La parcela. (Novela.) México, Imp. de V. Agüeros, Editor, 1898. $\mathrm{xxvi}, 542$, (3) pp., (colofón y erratas), más retrato. (Biblioteca de Autores Mexicanos, 11.)

Colofón: Acabóse de imprimir este libro el lunes 3 de enero de 1898, en la Imprenta de Victoriano Agüeros...

25 Obras... Tomo Ir. Novelas cortas. I. México, Imp. de V. Agüeros, Editor, 1900. x, 5-590 pp. (Biblioteca de Autores Mexicanos, 27.)

Contiene: "Introducción", del autor, y los cuentos Nieves, El primer amor, El espejo, En diligencia, Adalinda, El arpa, Un pacto con el diablo, La fuga, El brazalete, La suerte del bueno.

Dice López Portillo en la "Introducción" que estas novelas aparecieron por primera vez en La república literaria. Pero alli no se publicaron El brazalete ni La suerte del bueno. Un pacto con el diablo se publicó primero bajo el título La mueca del díablo. Véase el $\mathrm{N}^{\circ} 21$.

26 Obras... Tomo m. Novelas cortas. II. México, Imp. de V. Agüeros, Editor, 1903. v, (1), 5-605 pp., 2 h. (indice $y$ erratas más notables). (Biblioteca de Autores Mexicanos, 49.)

Contiene: "Un momento", el prólogo, y los cuentos El proscripto, El rector y el colegial, Pia, Luz de rayo, Sor María Margarita, La horma de su zapato, El dolor y la bonra, Egoísmo trágico, El billete de lotería, El pro $y$ el contra, Un drama en tres boras, Tres desenlaces ilógicos. Trae esta última los subtítulos siguientes: I. El brazo del coronel. II. Suprema fineza. III. Orvañanos. 
27 Obras ... Tomo iv. Los precursores. (Novela.) México, Imp. de V. Agüeros, Editor, 1909. xii, 722, ii pp. (Biblioteca de Autores Mexicanos, 69.)

Contiene, además de la novela: Dedicatoria a José María de Pereda, p. [v], con la siguiente nota: "Don José María de Pereda aceptó en vida esta dedicatoria y estaba dispuesto a poner prólogo a la novela; su enfermedad primero y su sentida muerte más tarde, le impidieron llevar a cabo el intento."

"Lo que es este libro", pp. [vii]-viii, con fecha: México, septiembre $1^{\circ}$ de 1908.

Una carta, sin dirección, p. [ix], firmada: El autor, México, diciembre de 1909.

28 Un pacto con el diablo. En los Nos. 21, 25.

29 La parcela. 1898. En el $\mathrm{N}^{9} 24$.

29 a —. Novela de costumbres mexicanas por el señor licenciado don José López Portillo y Rojas. México, Imprenta de "El Tiempo", 1904. (4), xiii, 302 pp., más ilustraciones.

"Prólogo", pp. i-vi. "Noticia biográfica del autor", sin firmar, pp. vii-xiii.

$29 \mathrm{~b}[-]$. Capitulo xı. En Antologia de la literatura mexicana. Introducción, selecciones y crítica de Carlos Castillo, Ph. D. ... Chicago, The University of Chicago Press, 1944, pp. 354-363.

$29 \mathrm{c} \longrightarrow$. Edición y prólogo de Antonio Castro Leal. México, Editorial Porrúa, S. A., 1945. xui, 400 pp., más colofón. (Colección de Escritores Mexicanos, 11.)

Colofón: Se acabó de imprimir este libro el 2 de mayo de 1945, en los talleres de la Editorial Stylo, ...

Dice el señor Castro Leal, hablando de esta edición, p. xii: Para nuestra edición hemos seguido el texto de 1904, corrigiendo sus errores y subsanando sus omisiones; además, nos hemos atrevido, en dos o tres casos en que nos pareció que no miejoraban el texto original, a no recoger en su integridad los cambios introducidos por el autor en la segunda edición. 
29d [La parcela]. Capítulo Ix. En Cutatro siglos de literatura mexicana. Seleccionada por Ermilo Abreu Gómez, Jesús Zavala, Clemente López Trujillo, Andrés Henestrosa. México, Editorial Leyenda, S. A., 1946, pp. 663-667.

30 Pía. En El renacimiento, segunda época (1894), pp. 183-186, 202-204.

Con fecha: Guadalajara, marzo de 1894.

En los Nos. 26, 47.

31 Por un caballo. En el $N^{\circ} 16$.

32 Los precursores. En, el $\mathrm{N}^{\circ} 27$.

33 El primer amor. En La rep. lit., año $\mathrm{mr}$, t. IV (marzo 88-marzo 89), pp. 85-94, 120-124, 156-160, 204-212, 253-256, 257265, 309-316, 407-416, 473-480, 502-518.

Cada entrega firmada: Yusuf-ben-Issa.

En los Nos. 25, 34.

34 El primer amor, El proscripto, El rector y el colegial. México, D. F., Editorial Salvador Chávez Hayhoe, 1945. 241 pp., 1 h. (índice). (Colección Internacional Clásicos de América, tomo $x_{\text {. }}$ )

"Prólogo" del ingeniero José López Portillo y Weber, pp. [7-18], con fecha: Agosto de 1945. Las páginas del prólogo y la dedicatoria que lo sigue están sin numerar.

35 El pro y el contra. En los Nos. 26, 47.

36. El proscripto. En los Nos. 26, 34, 47.

37 Puro chocolate. En el No 16.

38 Ramo de olivo. En Catentos mexicanos del siglo XIX. Selección, prólogo y notas bibliográficas de José Mancisidor. México, Editorial Nueva España, S. A., sin año. (Colección Atenea, 19), pp. 343-365.

En el $N^{9} 16$.

39 El rector y el colegial. En los Nos. 26, 34, 47.

39a —. En Torres-Rioseco, A., y E. R. Sims. Mexican short stories. Edited with introduction, notes and vocabulary by ... New York, Prentice Hall, Inc., 1932, pp. 51-65. 
El señor Torres-Rioseco se refiere a López Portillo en la introducción, p. xiv. Notas sobre el cuento, pp. 105-108.

40 Reloj sin dueño. En Cuentos mexicanos del siglo XIX. (Véase el $\mathrm{N}^{9} 38$. ), pp. 366-395.

En el $\mathrm{N}^{9} 16$.

41 Rincón bendito. En Reliquias de "América española". Suplemento a esa revista. Director... Licenciado Francisco Elguero. México, Escuela Tipográfica Salesiana, 1922, pp. 107-117.

Con fecha: México, abril 4 de 1922.

41a —. Cuento inédito. En El Universal Illustrado, núm. 316 (31 mayo, 1923).

42 Seis leyendas por .'. Edición de "Un periódico". Guadalajara, Tip. de Francisco Arroyo de Anda, 1883.

- -Iguíniz, Bibliografía de novelistas mexicanos.

43 ¡Silencio, corazón! En el $\mathrm{N}^{9} 16$.

44 Sor Maria Margarita. En los Nos. 26, 45-47.

45 Sor Maria Margarita y La borma de su zapato. Sus mejores novelas cortas. México, D. F., Publicaciones literarias de El Universal Ilustrado. $32 \mathrm{pp}$.

A la cabeza del título: La novela semanal de El Universal Ilustrado. Se publica cada jueves como suplemento de este semanario. Año 1.8 de junio de 1923. Núm. 32. Númeto dedicado a la memoria del novelista José López Portillo y Rojas.

-Iguiniz, Bibliografía de novelistas mexicanos.

46 Sor María Margarita. En Antologia de cuentos mexicanos. 1875 1910. Selección y notas por Joaquín Ramírez Cabañas. Buenos Aires-México, Espasa-Calpe Argentina, 1934. (Colección Austral, 358.), pp. 65-81.

Con una nota sobre el autor, p. 63.

47 Sucesos y novelas cortas por... Miembro correspondiente de la Real Academia Española e individuo de número de la Mexicana. México, Tipografía de "El Tiempo", 1903. v. (1), 5605 pp., 2 h. 
Idéntico al $\mathrm{N}^{\circ} 26$, con la excepción de la portada y posiblemente de la anteportada que faltaba en el ejemplar que he visto (de la biblioteca de la Ohio State University).

48 La suerte del bueno. En el $\mathrm{N}^{\circ} 25$.

49 Tres desenlaces ilógicos. En los Nos. 26, 47.

II. POESIA

50 A Elena Padilla. En El Renacimiento, segunda época (1894), p. 392.

51 A Hidalgo. En La rep. lit., año In, t. III (marzo 87-marzo 88), pp. 389-396.

En el $\mathrm{N}^{2} 60$.

52 A Manuel Gutiérrez Najera. En Revista azul, t. IV, núm. 16 (16 febrero, 1896), p. 243.

Con fecha: Guadalajara, enero 31 de 1896.

53 A Virginia Reiter. En La rep. lit., año $\mathrm{sv}, \mathrm{t} . \mathrm{v}$ (marzo 89. marzo 90), p. 238.

Con fecha: Guadalajara, junio 30 de 1889.

53a -... En Revista de México, año tercero, vol. tercero, núm. 41 (13 octubre, 1889), p. 528.

54 Adiós! [sic] En La rep. lit., año In, t. III (marzo 87-marzo 88), p. 335.

Firmada: Farfalla.

$I^{\text {as }}$ líneas: Es en vano luchar! Inútilmente

De tu amor y mi dicha corrí en pos: ...

En el $N^{9} 60$, sin título, forma parte de Más lieder, pp. 204-205. Compárese el $\mathrm{N}^{\circ} 100$.

En Armonias fugitivas ( $\mathrm{N}^{9} 60$ ), pp. 192-195, se halla otra poesía de título parecido: $A$ Diós. A mi padre el señor licenciado don Jesús López Portillo. $1^{7}$ línea: A ti, Ser inefable y escondido,... 
ss Alma natura. En La rep. lit., año If, t. IV (marzo 88-marzo 89), pp. $425-427$.

Con fecha: Junio de 1888. En el N 60 .

55a - En Antología de poetas mexicanos publicada por la Academia Mexicana correspondiente de la Real Española. Segunda edición, México, Oficina Tip. de la Secretaría de Fomento, 1894, pp. 330-332.

56 El amor del cielo. Leyenda. Por V. Farfalla. Guadalajara, Imp. de Gob., a cargo de J. G. Montenegro (hijo), 1884. 50 pp.

56 a - Poema. En La rep. lit., año III, t. IV (marzo 88-marzo 89), pp. 215-224, 230-244, 266-273.

57 Amor maldito. En La rep. lit., año I, t. II (septiembre 86-febrero 87 ), p. 279.

Firmada: Farfalla.

$1^{2}$ línea: Como la horrible boa...

En el $\mathrm{N}^{\circ} 60$, sin título, forma parte de Lieder, pp. 124125.

58 Apariencia y realidad. En La rep. lit., año I, t. 1 (marzo-agosto, 1886), p. 193.

Firmada: Farfalla.

$1^{2}$ linea: Eres bella, pareces inocente,...

En el $N^{\circ} 60$, sin título, forma parte de Lieder, p. 204.

59 Armonias fugitivas. En La rep. lit., año II, t. IV (marzo 88marzo 89), pp. 559-561.

Al fin: Guadalajara.

$1^{7}$ línea: Música alegre resuena..., En el $\mathrm{N}^{\circ} 60$.

60 Armonias fugitivas. Guadalajara, Est. Tip. de "La República Literaria", 1892. 320, (6). pp. (indice y'erratas), más retrato.

A la cabeza del título: José López Portillo y Rojas.

Contiene además: Un héroe. Poema, pp. 257-320.

En este tomo hay dos series de poesías, Lieder, pp. 124 127, y Más lieder, pp. 203-206, que se componen de 
versos antes publicados por separado y con títulos propios suprimidos aquí. Contiene Lieder las siguientes composiciones: Secreto (Nं 91 de esta bibliografía), Amor maldito (57), Traición (96), Destinos frustrados (67), Tú y yo (99). Componen Más lieder los siguientes: Cuando pasas (66), Confesión muda (64), Apariencia $y$ realidad (58), ;Adiós! (54), Vencido (100), iPerdón! (86).

61 La campana de Dolores. En Romancero de la guerra de independencia por varios autores. I. México, Imp. de V. Agüeros, editor, 1910. (Biblioteca de Autores Mexicanos, 71), pp. 347-359.

62 Campanas. A Manuel M. González. En La rep. lit., año Iv, t. v (marzo 89-marzo 90), pp. 46-48.

Con fecha: México, febrero 2 de 1889.

En el $N^{9} 60$ con el título Las campanas.

63 Las catacumbas. En La rep. lit., año II, t. III (marzo 87-marzo 88), pp. 380-387.

Con fecha: Roma, diciembre 19 de 1872.

En el $N^{\circ} 60$.

64 Confesión muda. En La rep. lit., año r, t. x (marzo-agosto, 1886), p. 173.

Firmada: Farfalla.

$1^{7}$ línea: Por la falda de piedra de la loma...

En el N 60, sin título, forma parte de Más lieder, p. 204.

65 ¡Cuán desdichada fuera nuestra suerte...! En La rep. lit., año Iv, t. v (marzo 89-marzo 90), p. 608.

Cuarteto sin título. He citado como tal el primer verso.

66 Cuando pasas. En La rep. lit., año II, t. III (marzo 87-marzo $88)$, p. 582.

Firmada: Farfalla.

$1^{*}$ línea: Cuando pasas radiante de hermosura,...

En el $N^{\circ} 60$, sin título, forma la primera parte de Más lieder, p. 203. 
67 Destinos frustrados. En La rep. lit., año II, t. III (marzo 87marzo 88), p. 356.

Firmada: Farfalla.

$1^{*}$ línea: En mí se hallaba la pasión latente...

En el $N^{9} 60$, sin título, forma parte de Lieder, p. 126.

68 El dolor. En La rep. lit., año I, t. I (marzo-agosto, 1886), pp. 418-421.

En el $N^{\circ} 60$.

69 Duelo incurable. En La rep. lit.; año I, t. II (septiembre 86-febrero 87), p. 288.

Firmada: Farfalla.

70 En el balcón. En La rep. lit., año II, t. III (marzo 87-marzo 88), p. 585 .

Firmada: Farfalla.

71 En la orilla del mar. En La rep. lit., año II, t. IV (marzo 88marzo 89), pp. 457-459.

72 En la sentida muerte del señor don José Palomar. En Corona fínebre del señor don José Palomar. Guadalajara, Tipografía de Dionisio Rodriguez, 1873, p. 41.

La compilación de este librito de 44 pp., estaba a cargo de Rafael Arroyo de Anda.

73 Entre la cuna y la tumba. En La rep. lit., año I, t. I (marzoagosto, 1886), p. 278 .

Firmada: Farfalla.

En el $N^{\circ} 60$.

74 Enturbiar la fuente. En La rep. lit., año 1 , t. I (marzo-agosto. 1886), p. 256.

Firmada: Farfalla.

En el $N^{\circ} 60$.

75 Eterna ausencia. En La rep. lit, año IV, t. v (marzo 89-marzo 90), pp. 293-294.

Con fecha: México, diciembre de 1888.

- En el N 60. 
76 La fortuna. En La rep. lit., año II, t. III (marzo 87-marzo 88), pp. 679-680.

En el $N^{\circ} 60$.

77 Un béroe: Poema. México, Imp. de Ignacio Cumplido, 1882. s5 pp.

En el $N^{\circ} 60$.

78 [Homenaje a José Martí]. En Martí, José. [Obras reunidas por Gonzalo de Quesada], t. vin. Norteamericanos. Gonzalo de Quesada, editor. La Habana, Imprenta y Papelería de Rambla y Bouza, 1909, p. 33.

En una sección con el encabezamiento: "Homenajes a José Martí. Almanaque Mexicano de Artes y Letras (1896)." $1^{*}$ linea: La inspiración en tu cerebro ardía...

Con fecha: Guadalajara, México, septiembre 16, 1895.

79 Jesucristo. En La juventud literaria, año Il, t. II, núm. 17 (22 abril, 1888), pp. 129, 132-133.

En el $N^{\circ} 60$.

79a - En La rep. lit., año In, t. IV (marzo 88-marzo 89), pp. 56-63.

80 La lluvia. En La rep. lit., año II, t. IV (marzo 88-marzo 89), pp. 373-374.

En el $N^{\circ} 60$.

81 Mágicas playas. En La rep. lit., año Im, t. IV (marzo 88-marzo 89), P. 280.

Firmada: Farfalla.

Con fecha: Junio 22 de 1888.

En el $\mathrm{N}^{\circ} 60$.

82 El mes de María. A la señora doña María Rojas de López Pottillo, mi adorada madre. En La rep. lit., año I, t. I (marzo- agosto, 1886), pp. 168-173.

Con fecha: Mayo de 1886.

En el $N^{\circ} 60$.

83 Mi tristeza. En La rep. lit., año ח, t. III (marzo 87-marzo 88), p. 429.

Firmada: Farfalla.

En el $\mathrm{N}^{\circ} 60$. 
84 Misterio! [sic] En La rep. lit., año I, t. I (marzo-agosto, 1886), p. 247.

Firmada: Farfalla.

85 iMuerta! En El siglo XIX, 9 noviembre, 1878.

-McLean, Malcom Dallas. El contenido literario de El siglo diez $y$ nueve. Tesis presentada... en la Escuela de Verano de la Universidad Nacional de México, 1938. 608 pp. (Escrita a máquina.)

86 Perdón! [sic] En La rep. lit, año II, t. II (marzo 87-marzo 88), p. 306.

Firmada: Farfalla.

$i^{7}$ línea: Buena como los ángeles, como ellos ...

En el $N^{9} 60$, sin título, forma parte de Más lieder, p. 206. En el $N^{\circ} .60$, pp. 49-52, hay otra poesía con el título Perdón.

A. R.... 1' línea: Visión primera de mis dulces sueños, ...

87 El poeta. A Juan de Dios Peza. En La rep. lit., año II, t. III (marzo 87-marzo 88), pp. 754-757.

Con fecha: Febrero 25 de 1888.

En el $N^{\circ} 60$ sin variaciones, pero faltando las estancias 4 , 6 , 14-19 y 23 (la última) del original.

88 El poeta y la mujer. En La rep. lit., año rv, t. v (marzo 89marzo 90), pp. 543-544.

En el $N^{\circ} 60$.

89 ¡El rey! En El federalista, edición literaria, t. x, núm. 6 (13 de agosto de 1876), p. 67.

90 Rie! [sic] En La rep. lit., año II, t. III (marzo 87-marzo 88), p. 571 .

Firmada: Farfalla.

91. Secreto. En La rep. lit,, año Ir, t. IIr (marzo 87-marzo 88), p. 65 .

Firmada: Farfalla.

$1^{2}$ línea: Es hermosa la mar, en sus cristales...

En el $N^{\circ} 60, \sin$ título, forma la primera parte de Lieder, p. 124. 
92 La serenata de Schubert. A Margarita Weber de López Portillo. En La rep. lit., año I, t. II (septiembre 86-febrero 87), pp. 189-192.

$1^{7}$ línea: Alza el patético inspirado canto,...

En el $\mathrm{N}^{\circ} 60$, con variaciones. $1^{\ddagger}$ línea: Alza, mi bien, el inspirado canto,...

93 ¡Socorro! A Aurelio Horta. Diálogo dramático. En La rep. lit., año IIr, t. IV (marzo 88-marzo 89), pP: 289-301.

Escrita para la función en beneficio de las víctimas de la inundación (18 junio, 1888) de León.

94 ¡Soñar! En La rep. lit., año II, t. IV (marzo 88-marzo 89), pp. 609-612.

En el $\mathrm{N}^{\circ} 60$, con variaciones y faltando la estancia $7 \mathrm{del}$ original.

95 Su tumba. En La rep. lit., año ח,.t. III (marzo 87-marzo 88), pp. 235-237.

Firmada: Farfalla.

Con fecha: 1880, Guadalajara.

En el $N^{\circ} 60$.

96 Traición. En La rep. lit., año I, t. I (marzo-agosto, 1886), p. 175.

Firmada: Farfalla.

$1^{7}$ línea: Cuando te hablaba yo del amor mío,...

En el $N^{\circ} 60$, sin título, forma parte de lieder, p. 125.

97 Las tres apoteosis de Margarita. En Revista moderna, año $\mathrm{V}$, núm. 5 ( $1^{*}$ quincena de marzo de 1901), p. 85.

Con fecha: Guadalajara, diciembre 27 de 1900.

Son tres sonetos: I. Aurora. II. Cenit. III. Ocaso.

98 Tres sonetos. En Revista moderna, año $x$, núm. S ( $1^{7}$ quincena de marzo de 1901), pp. 86-88.

Con fecha: Octubre 15 de 1889.

Los sonetos son: I. Fe. II. Esperanza. III. Caridad.

99 Tú y yo. En La rep. lit., año 1, t. I (marzo-agosto, 1886), p. 92.

Firmada: Farfalla. 
En el $N^{\circ} 60$, sin título, forma parte de Lieder, pp. 126-127.

$1^{*}$ línea: Me heriste sin piedad: una por una ...

100 Vencido. En La rep. lit, año ח, t. III (marzo 87-marzo 88), p. 584 .

Firmada: Farfalla.

$1^{\text {as }}$ líneas: Es en vano luchar! Inútilmente

Pretendi sofocar $\mathrm{mi}$ sentimiento,...

Compárese el $\mathrm{N}^{\circ} 54$.

En el $N^{\circ} 60$, sin título, forma parte de Más lieder, pp. 205-206.

101 Víctor Hugo en el Panteón. En La rep. lit., año I, t. I (marzoagosto, 1886), pp. 275-278.

En el $N^{\circ} 60$.

$101 \mathrm{a} \longrightarrow$. En La juventud literaria, año I, t. I, núm. 8, pp. 60-61.

102 Vivir para morir. En La rep. lit., año m, t. IV (marzo 88-marzo 89), pp. 153-155.

Con fecha: 1879.

103 Voces interiores. En -La rep. lit., año in, t. IV (marzo 88-marzo 89), pp. 10-12.

En el $N^{9} 60$, con variaciones y la añadidura de nueva estancia.

III. ARTICULOS LITERARIOS Y ARTisticos, PRoLogos, ETC.

104 [Carta]. En El renacimiento, segunda época (1894). En la cubierta de la $1^{7}$ entrega ( 7 enero, 1894), p. [iv].

Es una promesa de colaboración, fechada en Guadalajara, a 15 de diciembre de 1893.

105. [Carta]. En Cantú Corro, José. Soledad. Novela mexicana por el presbitero... Segunda edición. México, Antigua Imprenta de Murguía, 1923, pp. 6-7.

Bajo el encabezamiento: Carta de un insigne novelista que es Presidente de la Academia de la Lengua.

Fechada: México, septiembre 6 de 1921.

Felicita a J. C. C., por un libro sencillo y sano. 
106 [Cartas]. En Ríos Escalante, Manuel. Algunos rasgos característicos de América. Edición tercera. Unica corregida por el autor. Aguas Calientes, Tip. de la "Sociedad Católica", a. c. de A. Chávez, 1886, pp. v-vi.

Son tres cartas bajo el encabezamiento: Posteriores a la segunda edición son las siguientes cartas por el señor licenciado don José López Portillo y Rojas, ilustrado poeta, recomendable no sólo por su dedicación a las Letras, sino por el mérito de sus viajes.

Traen las fechas: Guadalajara, octubre 8 de 1877, mayo 14 de 1878 y noviembre 2 de 1879.

López Portillo agradece a Ríos Escalante el envio de las poesías de éste y le felicita por lo castizo de su estilo.

107 Contestación al discurso del señor Pbro. Federico Escobedo. Manzoni en México, discurso leido ante la Academia Mexicana. México, Imp. I. Escalante, S. A., 1917.

-Moore y Bickley, p. 42.

108 Elogio de Manuel José Otbón. Leido en la Academia Mexicana de la Lengua por... en sesión especial consagrada a este objeto, la noche del 22 de mayo de 1907. México, Imprenta de Ignacio Escalante, 1907. 55 pp., más retrato y facsimil de Othón.

Con fecha: México, mayo 22 de 1907.

108a _- En Memorias de la Academia Mexicana de la Lengua. México, Tip. de la Vda. de F. Díaz de León, Sucs. T. VI, (1910), pp. 182-228.

$108 \mathrm{~b} \longrightarrow$. En Othón, Manuel José. Obras. México, Secretaría de Educación Pública, 1928. T. r, pp. xv-xli.

109 [Gamboa, Federico. Sobre Reconquista. (?)] En El tiempo, 10 septiembre, 1908.

-Gamboa. Mi diario. IV. Segunda serie, t. I (1934), p. 299.

110 Julio Ruelas. En Revista moderna, año v, núm. 4 (2* quincena de febrero de 1902), Pp. 54-55. 
110 Julio Ruelas. En Revista moderna de México, t. Ix, núm. 2 (octubre, 1907), pp. 67-69.

111 Miguel Angel Buonarroti. En La rep. lit., año I, t. III (marzo 87-marzo 88), pp. 555-568.

112 La novela. Breve ensayo presentado a la Academia Mexicana. por... México, Tip. Vizcaino \& Viamonte, 1906. 62 pp.

Con fecha: México, agosto 4 de 1906.

112a - En Mémorias de la Academia Mexicana de la Lengua. México, Tip. de la Vda. de F. Díaz de León, Sucs. T. Iv (1910), pp. 49-103.

Nota en la página 49: Estudio leído por su autor ante la Academia Mexicana, en junta de 4 de agosto de 1905, al tomar posesión de la plaza de académico de número.

113 La novela en México. "La bola", por Sancho Polo. México, 1887. En La rep. lit., año II, t. III (marzo 87-marzo 88), pp. 433-443.

114 Unas palabras. En Acerca del autor que, viene a ser el prólogo a Delgado, Juan B. Paris y otros poemas. México, Imp. de I. Escalante, S. A., 1919, p. 7.

115 Un poeta potosino. Manuel José Othón. En El tiempo ilustrado, año vI, núm. 39 (29 septiembre, 1907), pp. 652 y 653.

-Monterde, p. 556.

116 Los poetas. En La rep. lit., año x, t. I (marzo-agosto, 1886), pp. 10-17, 42-48, 129-149.

Consideraciones generales sobre el tema.

117 Prólogo. En Berganzo, Luis Alfonso. El sol. Poema sáfico por L ... A . . B . . México, Imp. Victoria, 1921, pp. i-iv.

118 Prólogo. En Delgado, Juan B. Alma vernácula. México, Tip. Guerrero Hnos., 1914, pp. v-xiii.

Con fecha: México, a 28 de febrero de 1905.

119 Prólogo. En Rodríguez Beltrán, Cayetano. Cuentos costeños. Barcelona, Casa Editorial Sopena, 1905, pp. 7-20. 
El prólogo con fecha: México, julio 14 de 1905. Califica a Rodríguez Beltrán de costumbrista y de observador de ojo penetrante.

120 Prólogo. En Salado Alvarez, Victoriano. De autos. (Cuentos y sucedidos.) Guadalajara, Casa Impresora de J. R. García y Hnos., 1901, pp. vii-xi.

El prólogo con fecha: México, noviembre 22 de 1900.

121 Rafael Delgado. En El imparcial (Guadalajara), I, 313 (16 junio, 1892), p. 3.

-Moore y Bickley, p. 42.

122 Rosario la de Acuña. Un capítulo de historia de la poesía mexicana por José López Portillo y Rojas. México, D. F., Editada por "Librería Española", [1920]. 163 pp., índice y fe de erratas, (3) pp.

"Advertencia" con fecha: México, enero 19 de 1920.

123 El Sr. Lic. D. Fernando Nordensternau. En La rep. lit., año II, t. Iv (marzo 88-marzo 89), a la vuelta de una hoja entre las pp. 518 y 519 .

- Necrología del escritor. El índice cita por error la p. 520.

124 Vida brillante y breve. En La rep. lit., año II, t. III (marzo 87marzo 88), pp. $517-528$.

En la muerte de Manuel Alvarez del Castillo (16 febrero 1860-3 noviembre 1887). Biografía.

125 Virginia Reiter. En La rep. lit., año $\mathrm{rv}, \mathrm{t} . \mathrm{v}$ (marzo 89-marzo 90), pp. 225-230.

Sobre la actriz ítaloalemana.

126 La voz de María Guerrero. (Del "Domingo", de Guadalajara). En Revista moderna, año $\mathrm{MI}$, núm. 10 (2* quincena de mayo. de 1900), pp. 156-158.

\section{OBRAS DRAMATICAS}

127 Carne de cañón. Monólogo representado el 13 de febrero del año corriente en el Teatro Degollado por el aplaudido actor 
don Arturo Buxens. Guadalajara [sic], Imprenta de José Cabrera, 1894. 12 pP., $1 \mathrm{~h}$.

127a Carne de cañón. En El tiempo, t. Iv, núm. 137 (4 marzo, 1894), pp. 69 y 70 .

-Monterde, p. 197.

128 La Corregidora. Escena dramática representada por la señora Virginia Fábregas la noche del 15 de septiembre de 1899 en el Teatro Degollado de Guadalajara. Publicado en El domingo, 1899. Tomo I.

-Monterde, p. 197.

129 La venganza de Bravo. Epílogo de un drama. Representado por el distinguido actor don Arturo Buxens en el Teatro Degollado la noche del 21 de abril del presente año. Guadalajara, Imp. de "La Torre Eiffel" de Ignacio C. Garibay, 1893. 24 pp., $1 \mathrm{~h}$.

129a - (Epílogo de un drama.) Orizaba, Tipografía Popular. Aguilar y Co. [sic], 1894.

Es folletín de El reproductor, $2^{*}$ época, año xvm, t. xvn, núms. $12,13,14$.

129b . Epílogo de un drama. Monólogo patriótico escrito en verso. Orizaba, Tipografía Popular de Aguilar y Compañía, 1899. $20 \mathrm{pp}$.

-Monterde, p. 196.

\section{OBRAS VARIAS}

130 ;Abajo los toros! por ..., individuo de la Academia Mexicana de Ciencias Sociales... México, Imprenta de Mariano Viamonte, 1906. $48 \mathrm{pp}$.

Con fecha: México, mayo de 1906.

$130 \mathrm{a} \longrightarrow$. Principales pasajes de un folleto del licenciado... publicado en el año de 1906. Con licencia del autor... S. p. i. 28 pp.

(En la Biblioteca Bancroft de la Universidad de California.) 
131 Alegato presentado a la Suprema Corte de Justicia por el licenciado... en la revisión del fallo del juez primero de distrito de esta ciudad, que le negó amparo contra el auto de formal prisión dictado por el juez tercero de instrucción y confirmado por la quinta sala del Tribunal Superior de Justicia. México, Tipografía Económica, 1911. 57 pp.

Ocupan los "Anexos" las pp. 47-57. A la cabeza del título: En defensa propia.

132 Aztecas y espartanos. México, 1921. Libr. Porrúa Hnos. 22 pp. -Catálogo general de la librería española e hispanoamericana. Años 1901-1930. Autores. Madrid y Barcelona, Cámaras Oficiales del Libro, 1935. T. mI, ficha 47.158.

133 La baja de la plata. En La rep. lit., año I, t. II (septiembre 86febrero 87), pp. 161-178, 193-215.

134 Un buen libro. "Elementos de derecho internacional privado" por Francisco J. Zavala. En La rep. lit., año x, t. I (marzoagosto, 1886), pp. 271-274.

Revista de libro.

135 Confidencias intimas de notables literatos mexicanos. En Arte $y$ letras, año v่, núm. 88 (29 noviembre, 1908), p. 11.

Son contestaciones a una serie de preguntas estereotipadas con la firma en este caso de López Portillo y la fecha: Noviembre 24 de 1908.

136 Los chimalbuacanos. Discurso pronunciado por el señor licenciado don... En el Boletín de la Sociedad de Geografia y Estadística de la República Mexicana. Quinta época, t. vin, núm. 1 (julio y agosto de 1918), pp. 42-67.

Con fecha: México, diciembre 27 de 1917.

137 La defensa de la Bastilla. En La rep. lit., año $\mathrm{rv,} \mathrm{t.} \mathrm{v} \mathrm{(marzo}$ 89-marzo 90), pp. 276-288.

138 El derecho y la economía política. Breves reflecciones [sic] por ... Guadalajara, Imp. de Ancira y Hno., A. Ochoa, 1897. $100 \mathrm{pp}$., índice, $1 \mathrm{~h}$.

A la cabeza del título: Concurso científico nacional. 
139 Dinamita. En La rep. lit., año ill, t. Iv (marzo 88-marzo 89), pp. 546-550.

140 Discurso del señor licenciado don ...., socio de número de la Academia Mexicana de la Lengua, correspondiente de la Real de Madrid. Velada del 16 de abril de 1907. Puebla, Imprenta Artística, 1907. 13 pp., 1 h.

A la cabeza del título: Exposición Nacional de 1910. En la hoja final: Recuerdo de la Junta Directiva de la Exposición Nacional para 1910. Puebla.

141 Discurso (en velada pública a la presentación de don Rafael Delgado como Director General de Educación en el Estado [de Jalisco]. Guadalajara, 13 de enero de 1913).

-Moore y Bickley, p. 42.

142 La doctrina Monroe. Su verdadero sentido. Sus origenes. Su somnolencia. Su desarrollo. Su valor según el derecho constitucional norteamericano. Su valor en derecho internacional. México no debe admitirla. México, Imprenta I. Escalante, S. A., 1912. 47 pp., erratas notables, 1 h.

142a México, Tipografía Económica, 1912. 45 pp.

143 El duelo. En La rep. lit., año .II, t. III (marzo 87-marzo 88), pp. 587-597, 696-705.

En contra de los desafíos.

144 Egipto y Palestina. Apuntes de viaje. México, Imprenta de F. Díaz de León y S. White, 1874. 2 tomos.

145. Elevación y caíla de Porfirio Diaz por... Con un prólogo del señor licenciado don Atenedoro Monroy ... México, Editada por Librería Española, s. f. [1921]. 502 pp., indice, (2) $\mathrm{pp}$.

En la cubierta: Primera edición.

146 El Emperador de Alemania. En La rep. lit., año II, t. IV (marzo 88-marzo 89), pp. 13-19.

Sobre Guillermo 1 .

147 En la apertura de la Exposición de Guadalajara. En La tribuna, t. II, núm. 201 (21 mayo, 1880), pp. 1-2.

Discurso. 
148 Enrique VIII de Inglaterra. México, 1921.98 pp.

-Palau y Dulcet, Manual del librero bispanoamericano, t. 4, p. 272. Se refiere también a este opúsculo en Biblos, $t$. III, núm. 128 (2 julio, 1921), p. 107.

149 Ensayos económicos. México, Tip. "El Tiempo", 1910. 374 pp. Contiene: "John Bright", "La economía política y el derecho", "La grandeza de Inglaterra" y "Pobres y ricos".

150 La filosofía en la Nueva España. En La rep. lit., año In, t. III (marzo 87-marzo 88), pp. 197-215.

Véase el $\mathrm{N}^{\circ} 156$.

151 Introducción bibliográfica. En Tello, fray Antonio [i. e., Juan Antonio]. Libro segundo de la Crónica miscelánea, en que se trata do la conquista espiritual y temporal de la Santa provincia de Xalisco en el Nuevo Reino de la Galicia y Nueva Vizcaya y descubrimiento del Nuevo México, compuesto por... Guadalajara, Imprenta de "La República Literaria"; de C. L. de Guevara y Cía., 1891, pp. i-xxiv.

La introducción con fecha: Guadalajara, noviembre 10 de 1891.

"Algunos ejemplares llevan el siguiente título: Historia general de Jalisco que trata de la conquista en el Nuevo Reino de la Galicia y Nueva Vizcaya y Descubrimiento del Nuevo México escrita por fray Antonio Tello con una introducción bibliográfica de José López Portillo y Rojas.-Guad., Méx.; 1894. Débese tal e impropia suplantación al librero don Eusebio Sánchez, quien la hizo con el objeto de obtener la venta de mayor número de ejemplares, en vista de un título más amplio y general:" -Iguíniz, Los bistoriadores de Jalisco, p. 23, nota 2.

152 Jobn Bright. En Revista nacional de letras $y$ ciencias, t. I (1889), pp. 221-240.

Con fecha: Guadalajara, abril de 1889. Las páginas tienen por error los números 121-140.

153 Lais XVII. En La rep. lit., año II, t. II (marzo 87-marzo 88), pp. 309-323, 339-353. 
154 El monoteismo de los bebreos por ..., individuo de la Academia Mexicana de Ciencias Sociales. México, Talleres Tipográficos de "El Tiempo", 1907. 52 pp.

Con fecha: México, febrero $1^{\circ}$ de 1907.

155 Oración finnebre pronunciada en el Panteón de Dolores... [en los funerales del señor don José M. Vigil, el 20 de febrero de 1909]. En Boletín de la Biblioteca Nacional de México, número extraordinario (febrero de 1909), pp. 10-12.

156 El peripatetismo en acción. En La rep. lit., año n, t. In (marzo 87-marzo 88), pp. 245-256.

Es una respuesta al periódico quincenal La religión y la sociedad, de Guadalajara, que atacó a López Portillo por su artículo La filosofía en la Nueva España.

Véase el $\mathrm{N}^{2} 150$.

157. Las pirámides (Piramah). En Teixidor, Felipe, comp. Viajeros mexicanos. (Siglos $\mathrm{xIX}$ y $\mathrm{xx}$.) México, Ediciones Letras de México, 1939, pp. 77-91.

Es una selección de su libro Egipto y Palestina. (Véase el $\left.\mathrm{N}^{\circ} 144\right)$, y viene precedida de una nota, "José López Portillo y Rojas (1873)."

Véase el $\mathrm{N}^{0} 38$ de la segunda parte de esta bibliografia.

158 El quinto estado de la graduación mercantil, 1885.

-Biblos, t. I, núm. 37 (27 septiembre, 1919).

159 Rafael Arroyo de Anda. En El eco social (Guadalajara), 28 jutinio, 1879.

-Iguíniz, El periodismo en Guadalajara, pp. 302 y 324.

160 La raza indigena. Breves reflexiones. México, Imprenta Mariano Viamonte, 1904. $59 \mathrm{pp}$.

Con fecha: México, agosto $1^{\circ}$ de 1904 . Comentario sobre la obra de Francisco Pimentel.

161 El Sr. General D. Ramón Corona. En La rep. lit., año Iv, t. $\mathrm{v}$ (marzo 89-marzo 90), pp. 500-508.

Sobre el asesinato del general. 


\section{TRADUCCIONES}

162 Craven, Augustus. Mad[ame]. El padre Damián, por Mad. Augustus Craven, nacida la Ferronays. Versión española de José López Portillo y Rojas.

Editores: Francisco Torres y Cía. Guadalajara, "La Torre Eiffel".

-Tip. de Francisco Torres y Cía., 1891. xxix, 145 pp., $1 \mathrm{~h}$.

Contiene, por vía de prólogo: ¡Sursum!, pp. v-xxix, firmada: El traductor.

163 Elste, RaidP. La bermana de Miss Darrell. En La rep. lit., año III, t. IV (marzo 88-marzo 89), pp. 562-568, 605-608, 711719.

Al fin: Ralph Elsie. (Traducido del inglés por.J. L. P. y R.) La entrega final y el índice traen el nombre "Darrel" en el título.

164 Varigny, C DE. México en la Exposición de Paris. En La rep. lit., año $\mathrm{rv}, \mathrm{t} . \mathrm{v}$ (marzo 89-marzo 90), pp. 609-613.

Dice el traductor: $\mathrm{De}$ un artículo publicado por Mr. C. de Varigny en la Revue de deux mondes bajo el título de La América en la Exposieión [sic], traducimos lo siguiente...

165 Taine, H[TPpolyte]. Napoleón Bonaparte. Primera parte. En La rep. lit., año II, t. III (marzo 87-marzo 88), pp. 573-582, 605-613, 641-648, 671-678; año $\mathrm{In}$, t. IV (marzo 88-marzo 89), pp. $42-46$.

Una nota en la página 42 de la última entrega dice: Terminamos hoy la primera parte...

La segunda parte de esta traducción la hizo Victoriano Salado Alvarez. Al fin, t. IV, p. 501, se halla: Por la versión española de la primera parte, José López Portillo y Rojas.

$165 \mathrm{a} \longrightarrow$ Psicologia de los jefes jacobinos. (Por H. Taine.) En La rep. lit., año I, $t$. I (marzo-agosto, 1886), pp. 346-358, 361-371, 393-417.

Al fin: (Versión española de J. L. P. y R.) 


\section{SEGUNDA PARTE - TRABAJOS REFERENTES A LOPEZ PORTILLO}

1 Amézaga, Carlos G. Poetas mexicanos. Buenos Aires, Imprenta de Pablo E. Coni e Hijos, Mdcccxcv1, pp. 342-347.

Cita la poesía ;Orad!

2 Anónimo. Escritores mexicanos contemporáneos. Licenciado don José López Portillo y Rojas. En Biblos, t. I, núm. 37 (27 septiembre, 1919), pp. 1-2.

Con una bibliografía bastante inexacta.

3 - Historias.-Historietas y cuentecillos, por José López Portillo y Rojas.-Libreria de la Vda. de Ch. Bouret.-México.-1918. En Biblos, t. I, núm. 6 (22 febrero, 1919), p. 3.

Es una reseña.

4 - Excmo. Sr. Lic. don José López Portillo y Rojas. En $2^{\prime}$ conferencia panamericana. Crónica social, 1901. México, F. Laso y Cía., Imps., [1902 ?], pp. 133-135.

.5 [Carpio, Manuel]. Hombres de letras. Licenciado don José López Portillo y Rojas. Por Juan de Linza. En Crónica (Guadalajara), año I, núm. 5 ( $1^{\circ}$ marzo, 1907), Pp. 55-56.

-Moore, Obras criticas, ficha 51 .

6 Carreño, Alberto María. La Academia Mexicana correspondiente de la Española. En Memorias de la Academia Mexica$n a$ correspondiente de la Española. Tomo séptimo. México, 1945.

Colofón: Terminada la primera parte de este trabajo desde el año de 1925, se concluyó la impresión de este volumen el 29 de marzo de 1946 en los Talleres Gráficos número 1 de la Secretaría de Educación Pública.

El tomo 7 de las Memorias consiste exclusivamente en el estudio del señor Carreño. Hay muchas referencias a López Portillo. La más importante es una biografía, pp. 157-159. 
7 Carreño, Alberto María. Don José López Portillo y Rojas. En América española, vol. 1 , núms. 4 y 5 (15 junio, $1^{\circ}$ julio, 1921), pp. 260-267, 340-346.

-Dato de Ernest R. Moore:

8 Don José López Portillo y Rojas como novelista. En Revista de revistas, XIv, 681 (1923), 50; 682, 48-49.

-Moore, Obras críticas, ficha 52.

Es un elogio pronunciado el 9 de abril de 1921 en una velada especial de la Academia Mexicana en honor de don José.

$8 \mathrm{a}$ - El licenciado José López Portillo y Rojas. Prosista. México, Imprenta Victoria, S. A., 1923. 24 pp., más retrato. El prólogo trae la fecha: México, junio de 1923.

9 Castañeda, Alfonso Manuel. Los regionalismos de "La parcela" del Lic. D. José López Portillo y Rojas. En Investigaciones linguiisticas, t. Iv, núms. 1-2 (enero-abril, 1937), pp. 63-69.

Dice el investigador: " $\mathrm{La}$ edición que me ha servido para este 'Ensayo', es la que editó la imprenta de 'El Tiempo', de la ciudad de México, en la 'Biblioteca Agüeros', en' el año de 1904. Essta edición consta de 302 páginas."

Se refiere a la edición de 1904, en efecto, pero que no forma parte de ninguna "Biblioteca Agüeros", aunque sí fué editada por don Victoriano. Fallan algo las citas de Castañeda para la exactitud literal como para la exactitud de la paginación de ellas.

10 Congreso de la Unión. XXIV Legislatura. Cámara de Diputados. Dictamen que la $1^{*}$ sesión instructora presenta al Gran Jurado Nacional en el proceso instruído al senador licenciado José López Portillo y Rojas. 1909. 34 pp.

Sin pie de imprenta.

11 Coester, Alfred. The literary bistory of Spanish America. Second edition. New York, The Macmillan Company, 1928, pp. $366-367,490$.

12 Fernández, JosÉ Diego. Acusación contra el señor senador Lic. don José López Portillo y Rojas. Defensa producida por 
el señor licenciado don José Diego Fernández. Discurso pronunciado por el jurado señor ingeniero don Agustín Aragón. Anexos. México, Tip. de Müller Hnos., 1909. 78 pp., 1 h., lxxvi pp.

A la cabeza del título: Ante el Gran Jurado. "Anexos", lxxvi pp.

13 Funness, Edna Lue. Literary theories of José Ĺópez Portillo $y$ Rojas. Tesis de maestra. Universidad de Colorado, 1940. iv, $90 \mathrm{pp}$.

Escrita a máquina.

14 Gambon, Federico. Mi diario. IV. Segunda sërie, t. I, México, Eusebio Gómez de la Puente, 1934.

Páginas 285-286: Invitación de L. P. y R., secretario de la Academia Mexicana, a que concurra Gamboa a las sesiones. Página 299: "Ha seguido la benevolencia ... para juzgar el tomo I de Mi diaria y mi novela Reconquista. En 'El 'Tiempo' de hoy, muy jugoso artículo de Pepe López Portillo.y Rojas,...

Página 313: Se refiere a un juicio de Reconquista leído por L. P., en la sesión del Liceo Altamiràno, de 11 de octubre de 1908.

15 . Idem. V. Segunda serie, t. II. México, Ediciones Botas, 1938.

Página 17: Le comunica su amigo L. P., su elección como miembro de número de la Academia Mexicana.

Páginas 113-115: Contrariedad de Gamboa por el encarcelamiento de L. P., que atribuye a "artimaña política" de los "científicos".

Páginas 128, 144: Lamenta el encarcelamicnto de L. P.

16 González Obregón, Luis. Breve noticia de los novelistas mexicanos en el siglo XIX. En El Liceo Mexicano, t. II, núm. 17 (15 junio, 1887), p. 130.

Habla de L. P., en la parte LXvi.

17 González Peña, Carlos. Historia de la literature mexicana desde los orígenes hasta nuestros días. Tercera edición corregida y aumentada. México, Editorial Porrúa, S. A., 1945, pp. 342-344. 
18 Herrera, Modesto L. Voto pärticular del diputado M.... L. H. ..., miembro de la Primera Sesión instructora del Gran Jurado, en la acusación hecha al señor senador José López Portillo y Rojas. 8 p.

Sin pie de imprenta.

19 Hespelt, E. Herman, comp. An outline bistory of Spanish American literature. Prepared under the auspices of the Instituto Internacional de Literatura Iberoamericana, by a committee consisting of E. Herman Hespelt, Chairman and Editor, Irving A. Leonard, John E. Englekirk, John T. Reid, John A. Crow. Second edition. New York, F. S. Crofts \& Co., 1942, p. 111.

20 Hollingshead, Laura A. Mexican life as depicted in the novels of José López Portillo y Rojas. Tesis de maestra. Universidad de Washington (St. Louis Missouri), 1931.

-Moore, Obras criticas, ficha 154.

21 GonZález ObRegón, Luis. Breve noticia de los novelistas mexicanos en el siglo XIX. En El liceo mexicano, t. II, núms. 7, 10, 13 y 17 (enero-junio, 1887).

López Portillo en el núm. 17 (junio 15), p. 130.

21a I Iem. México, Tipografía de O. R. Spíndola y Comp., 1889. Edición de 100 ejemplares.

"José López Portillo y Rojas", pte. Lxxvm, pp. 52-53.

22 Elguero, Francisco. Una bella página del señor Lic. don José López Portillo y Rojas. En Excelsior (México), 26 mayo, 1923.

-Iguíniz, El periodismo en Guadalajara, pp. 340-341, 350.

23 Iguiniz, Juan B. Bibliografía biográfica mexicana. Tomo x. México, Imprenta de la Secretaría de Relaciones Exteriores, MCMxxx. xi, 546 pp. (Monografías Bibliográficas Mexicanas, núm. 10.)

24 - Bibliografía de novelistas mexicanos. México, Imprenta de la Secretaría de Relaciones Exteriores, Mcmxxvi. (Monografías Bibliográficas Mexicanas, núm. 3), pp. 192-197. 
25. IquínIz, JuAN B. Los bistoriadores de Jalisco. Epítome bibliográfico. México, Oficina Impresora de la Secretaria de Hacienda, 1918. 114 pp., más retratos.

Contiene varias referencias al Libro segundo de la cróni$c a \ldots$ de fray Antonio Tello con introducción de López Portillo.

26 - El periodismo en Gutadalajara. 1809-1914. Recopilación de datos históricos, biográficos y bibliográficos, por ... En Anales del Museo Nacional de Arqueologia, Historia y Etnografía. Epoca $4^{3}$, t. vII, núm. 2 (enero a diciembre, 1932). Menciona a López Portillo con frecuencia, especialmente en las pp. 337-339, donde habla de La repuiblica literaria, y en la sección dedicada a López Portillo, pp. 339-341.

27 Jarnés, Benjamín. Manuel Actiña, poeta de su siglo. México, Ediciones Xóchitl, 1942. (Vidas Mexicanas, 6.), pp. 136-138. La mayor parte de estas páginas es una cita algo inexacta de Rosario, la de Acuña, pp. 58-59.

28 Jiménez Rueda, Julı. Historia de la literatura mexicana. Cuarta edición. México, Ediciones Botas, 1946, p. 254.

29 - Letras mexicanas en el siglo XIX. México, Fondo de Cultura Económica, 1944, pp. 164-165.

30 Maples Arce, Manuel. El paisaje en la literatura mexicana. México, Librería de Porrúa Hnos. y Cía., 1944, pp. 36-37. Consiste principalmente en una selección de La parcela.

31 Monterde, Francisco. Bibliografía del teatro en México. México, Imprenta de la Secretaría de Relaciones Exteriores, MCMxxxuI. lxxx, 650, (2) pp. (Monografías Bibliográficas Mexicanas, núm. 28).

Colofón: ... se terminó de imprimir el 10 de marzo de $1934 \ldots$

32 MoORe, ERNest R. Studies in the Mexican novel. Tesis de doctor en filosofía. Cornell University. Ithaca, N. Y., 1940. 420 pp., más 24 de bibliografía.

Con un capítulo sobre López Portillo. 
33 Peza, Juan DE Dios. Poetas y escritores de México. Revista contemporánea original de... F. Mata, editor. México, 'Tipografía Literaria, 1878 , p. 66.

La página [3] de este libro trae el título: Poetas y escritores modernos mexicanos. Se refiere Peza a López Portillo meramente como poeta y autor de Egipto y Palestina.

34 Puga y Acal, Manuel. [José López Portillo y Rojas. Poeta.] Elogio en la velada de la Academia Mexicana en honor de López Portillo, abril de 1921.

Dato de Carreño en la p. 3 del $\mathrm{N}^{\circ} 8$ a de esta parte.

35 Salado Alvarez, Victoriano. La parcela. En De mi cosecba. Estudios de crítica. Guadalajara, Imp. de Ancira y Hno. A. Ochoa, mDcccxcix, pp. 51-57.

36 Serrano, Pedro. Lic. José López Portillo y Rojas. En Hispanistas mexicanos. I volumen. México, [Imprenta Nacional], 1920, pp. 33-38.

Es una entrevista periodística.

37 STARR, FREDERICK. Readings from modern mexican autbors. Chicago, The Open Court Publishing Company, 1904, pp. 313-333.

Breve biografía y.resumen de La parcela, pp. 313-316; traducción de selecciones de dicha novela, pp. 316-333.

38 [Tablada, José Juan]. "La raza indigena", por José López Portillo y Rajas. En Revista moderna de México, vol. m, núm. 3.

Revista firmada: J. J. T.

39 Terxinor, Felipe. Viajeros mexicanos. (Siglos xix y xx.) México, Ediciones Letras de México, 1934, pp. 75-76.

Es una nota sobre López Portillo acompañando una selección de su libro Egipto y Palestina. Véase el $\mathrm{N}^{9} 157$ de la $1^{2}$ parte.

40 Torres-Rioseco, Arturo. La novela en la América Hispana. Berkeley, University of California Press, 1939. (University of California Publications in Modern Philology, vol. 21, $N^{\circ} 2$, pp. 159-256), p. 200. 
41 YANCEY, MYRA LoIs. Literary biograpbies of nineteenth century. México (1800-1910.) Tesis de doctora en filosofia. Universidad de Colorado, 1939, pp. 350-351, 367, 417, 449, 494, $515 ; 535-536,626-628$.

42 Zea, Leopoldo. Apogeo y decadencia del positivismo en México. México, El Colegio de México, 1944. 303 pp.

Cita varias veces la Elevación y caida de Porfirio Díaz. 